\title{
Médiévales
}

Langues, Textes, Histoire

63 | automne 2012

Philosophies morales

\section{Vie de Charles IV de Luxembourg, éd. et trad. Pierre MONNET et Jean-Claude SCHMITT}

Paris, Les Belles Lettres, 2010, 277 p. (Classiques de l'histoire au Moyen Âge, 49)

\section{Éloïse Adde-Vomáčková}

\section{Q OpenEdition}

1 Journals

\section{Édition électronique}

URL : https://journals.openedition.org/medievales/6908

DOI : 10.4000/medievales. 6908

ISSN : $1777-5892$

\section{Éditeur}

Presses universitaires de Vincennes

\section{Édition imprimée}

Date de publication : 15 décembre 2012

Pagination : 182-183

ISBN : 978-2-84292-353-2

ISSN : 0751-2708

\section{Référence électronique}

Éloïse Adde-Vomáčková, « Vie de Charles IV de Luxembourg, éd. et trad. Pierre monnet et Jean-Claude sснмітт », Médiévales [En ligne], 63 | automne 2012, mis en ligne le 15 janvier 2013, consulté le 24 avril 2022. URL : http://journals.openedition.org/medievales/6908 ; DOI : https://doi.org/10.4000/ medievales. 6908

Ce document a été généré automatiquement le 24 avril 2022.

Tous droits réservés 


\section{Vie de Charles IV de Luxembourg, éd. et trad. Pierre MONNET et Jean- Claude SCHMITT}

Paris, Les Belles Lettres, 2010, 277 p. (Classiques de l'histoire au Moyen Âge, 49)

\section{Éloïse Adde-Vomáčková}

1 Très attendu, ce livre se propose en premier lieu de remédier à l'inaccessibilité de la Vita Caroli pour le public français. Le travail de Pierre Monnet et de Jean-Claude Schmitt constitue en effet la première traduction vers le français de ce texte pourtant fondamental pour l'histoire de l'Occident en général. La traduction a été entreprise par les deux co-auteurs dans le cadre de l'ANR «Une culture du Livre dans une société d'illettrés. Parler, figurer, écrire dans l'Europe médiévale», implantée au GAHOM (Groupe d'Anthropologie Historique de l'Occident Médiéval de l'École des Hautes Études en Sciences Sociales).

2 L'ouvrage se compose d'une introduction de 98 pages, à laquelle succède le texte de l'autobiographie de Charles IV (1316-1378) (179 pages). Ce premier tronçon dépasse largement les objectifs d'une introduction classique et fournit aux lecteurs une bonne synthèse (p. I-LIV) sur le projet littéraire de Charles IV et les enjeux de la rédaction de son autobiographie, définie avec justesse comme le résultat d'un triple travail, «celui du rêve, celui de la mémoire et celui de l'écriture» (p. XLIX). Au-delà de la compréhension du projet du roi de Bohême et empereur du Saint-Empire romain germanique (1346-1378), c'est la personnalité contrastée de cet individu, à la fois royal et chrétien, acteur du faste de la cour et adepte de l'ascèse, mais encore féru de savoir et lettré, que les auteurs ont également cherché à restituer. Si l'autobiographie royale n'était plus une première dans l'Europe du XIv siècle, les auteurs insistent sur la spécificité de celle de Charles qui, contrairement aux autres souverains, adopta le latin pour rédiger la sienne et innova encore dans ses choix formels en s'écartant du modèle traditionnel des Miroirs aux princes, pour créer un genre tout à fait personnel. La Vita alterne des styles et des modes variés, du traité politique à l'homélie, en passant par le 
récit événementiel, et s'emploie à donner l'image la plus complète du métier de prince dans le but d'être utile, un jour, aux successeurs de l'auteur. Pierre Monnet et JeanClaude Schmitt ont également réalisé un travail précis sur les manuscrits conservés de la Vita, et nous livrent une étude fine des différentes miniatures qu'ils contiennent (p. LIV-LXXII), prenant en considération les manuscrits tant latins que tchèques, ce qui témoigne d'un effort louable de cerner le sujet de la manière la plus complète possible. Ces miniatures permettent aux auteurs de signaler la vive attention du souverain à multiplier les portraits de sa personne, des portraits, qui plus est, authentiques qui rompent résolument avec les canons médiévaux. L'introduction se clôt sur la présentation des manuscrits et des éditions de la Vita (p. XXXII-LXXXVII). Quatorze manuscrits sont conservés aujourd'hui. Le manuscrit autographe a disparu. C'est le ms. Cod. 556 (Bibliothèque nationale d'Autriche), vraisemblablement rédigé du vivant de Charles IV, qui sert de référence au travail d'édition et de traduction. Les deux auteurs complètent leur tour d'horizon par une présentation des éditions des autres écrits littéraires du souverain ainsi que des actes royaux et impériaux produits durant son règne, en prodiguant un traitement tout particulier à la célèbre Bulle d'Or de 1356. Signalons enfin la riche bibliographie, intercalée entre le texte de l'introduction et la traduction, qui procure au lecteur un inventaire exhaustif des publications en français, en allemand, en tchèque et en anglais sur le règne de Charles IV et les sujets divers qui s'y rattachent.

3 Pierre Monnet et Jean-Claude Schmitt ont fait le choix judicieux de proposer une édition bilingue de la Vita. On apprécie le système double des notes de bas de page, qui permet de bien distinguer les commentaires d'ordre codicologique et les compléments d'information relatifs au contexte et aux aspects historiographiques. Les deux textes, latin et français, sont disposés sous la forme d'un miroir qui permet un va-et-vient aisé entre le support et sa traduction, et constitue un outil très utile pour l'historien. Audelà de la traduction vers le français du texte majeur que représente la Vie de Charles IV, les deux auteurs nous offrent une belle édition du texte original latin, entreprise qui, soulignons-le, n'avait pas été réalisée depuis l'édition maîtresse de 1882 du philologue tchèque Josef Emler. 